\title{
El desarrollo local endógeno en tiempos de globalización: aproximaciones teóricas y desafíos prácticos
}

Local endogenous development in a context of globalization: theoretical approaches and pragmatic challenges

\author{
RAúl GonzÁlez MEYER \\ Universidad Academia de Humanismo Cristiano, Chile \\ Stefano Micheletti \\ Universidad Católica del Maule, Chile
}

RESUMEN El artículo propone una reflexión sobre la re-conceptualización de lo local en un contexto de globalización, y analiza en términos teóricos cuáles son las posibilidades efectivas de que se mantengan, refuercen o desencadenen dinámicas de desarrollo local endógeno, entendido como proceso con alto protagonismo de las sociedades locales y, también, como enfoque alternativo. El trabajo se basa en la revisión de la literatura sobre desarrollo local y globalización, y pretende ser un aporte a la discusión sobre estos tópicos. El texto constata la existencia de enfoques que conceptualizan lo local destacando fenómenos como el descentramiento, las redes supra locales, el reforzamiento de las capacidades competitivas de los territorios, el sentido comunitario y las identidades. Planteamos que éste debe entenderse como un "complejo de locales" que pueden tener relaciones entre sí, que el territorio se produce socialmente, y que para adquirir algún carácter de alternatividad en un contexto globalizado, los procesos de desarrollo local endógeno tienen que contar con agentes locales fortalecidos y que actúan desde diversas escalas de la realidad. Destacamos además el rol de los agentes externos: las acciones en y desde escalas mayores pueden ser elementos clave si están en concordancia con orientaciones provenientes de lo local.

PALABRAS CLAVE Teoría del desarrollo; desarrollo económico y social; desarrollo regional; desarrollo local. 
ABSTRACT This article proposes a reflection on the re-conceptualization of the local in a context of globalization, and analyzes, in theoretical terms, what the effective possibilities of maintaining, reinforcing or triggering dynamics of local endogenous development are. The latter understood, in broad terms as a process with high prominence of local populations and societies and, at the same time, as an alternative approach. The work is based on the review of literature on local development and globalization, and aims to be a contribution to the discussion on these topics. The review confirms the existence of approaches that conceptualize the local, highlighting phenomena such as decentration, supra local networks, the strengthening of the competitive capacities of the territories, the community sense and identities. We suggest that this should be understood as a "complex of premises" that can be interrelated; that a territory is socially produced; and that, in order to acquire some character of alternativeness in a globalized context, endogenous local development processes must have strengthened local agents acting from different scales of reality. At the same time, we emphasize the role of external agents: actions on and from larger scales can be key elements if they are in accordance with orientations coming from the local.

KEYWORDS Develoment theory; economic and social development; regional development; local development.

\section{Introducción}

Este trabajo analiza en términos teóricos cuáles son las posibilidades efectivas de que -en un contexto globalizado- se mantengan, refuercen o desencadenen dinámicas de desarrollo local endógeno, entendido este último -en términos muy generales- como un proceso con alto protagonismo de las poblaciones y sociedades locales y, a la vez, por ello, como un enfoque alternativo de desarrollo.

En términos metodológicos, se trabaja buscando reconstruir retrospectivamente cada tipología de valorización de los territorios locales a través de un proceso de revisión bibliográfica de la literatura disponible, referenciando los autores más destacados. Para la construcción de las diferentes categorías se aplicó un mismo esquema, que consistió en la identificación de la relación que se establece entre lo local y lo global desde el punto de vista teórico, y el impacto de esta relación en los territorios locales. Posteriormente, y a partir del esquema propuesto, se formulan un conjunto de propuestas que - desde nuestra perspectiva- son esenciales para que las sociedades locales puedan adquirir un alto protagonismo en las dinámicas de desarrollo local y en un contexto globalizado. El artículo cierra con un apartado de conclusiones. 
Nuestra premisa es que aquello que denominamos como local es una categoría construida, cuya definición no está dada en términos puramente de límites físicos sino del conjunto de interacciones que allí se dan y que le dan a ese espacio una existencia social concreta, en términos de una escala y escena de lo social.

En este sentido, el concepto de lo "local", como una escala de lo "social" (Arocena, 2002) puede ser pensado abordando sus dimensiones principales en un contexto de globalización, tratando de entender cómo -o bajo qué condiciones- el desarrollo local puede tener características democráticas y sustentables. En concordancia con ello, el concepto hace referencia a un espacio teórico-político de disputa y de discusión de orientaciones y significados. En ese marco ubicamos corrientes de carácter más o menos alternativo, que valorizan lo autónomo y el "desde abajo", pero asumiendo la existencia de un mundo con fuertes interdependencias asimétricas, donde la gestión de esa interdependencia ha pasado a ser clave para pensar y plantear una mayor endogeneidad (democrática y sustentable) local.

\section{Interpretaciones teóricas sobre la reconceptualización de lo local en un con- texto de globalización}

Diversos debates se han embarcado en despejar la encrucijada de determinar si lo local y lo global son conceptos y órdenes opuestos y excluyentes, o si se producen espacios de encuentro, tanto en lo teórico como en lo práctico. De esto, deriva una serie de discusiones sobre como reconceptualizar la realidad de lo local en este contexto globalizado, en red, interdependiente.

La globalización es el resultado de diversas fuerzas: la emergencia de una masa crítica mínima de grandes empresas cuya escala de acción es el mundo; los avances científicos y tecnológicos en comunicaciones y transporte; la reestructuración política y administrativa del Estado y los gobiernos que abren fronteras; la demanda de actores organizados de la sociedad civil por la defensa o la conquista de modos de vida; la tendencia a la privatización de las actividades productivas y la extensión del mecanismo del mercado (Boisier, 2005). Es un fenómeno, por ello, que presenta múltiples dimensiones. La globalización puede ser caracterizada como una fase del capitalismo y la economía-mundo, que expresa la naturaleza expansiva de aquel, pero también como un conjunto de cambios tecnológicos e institucionales que generan nuevas concentraciones y centralizaciones del capital.

Ello significa una enorme extensividad e intensidad de lazos de todo tipo a escala mundial, entre puntos ubicados en distintos espacios. Lo "inter" tiende a generar un espacio donde todo se transforma, en mayor grado, en "intra". Producto de este proceso de globalización que intensifica la relación entre territorios locales a escala 
mundial, estos se reconfiguran dando lugar a diferentes lecturas de cómo quedan articulados "lo local" con lo "global".

\section{Descentramiento, disolución o alienación de lo local-territorial}

Una de estas aproximaciones es la de la "disolución" o, al menos, fuerte debilitamiento de lo local-territorial, dado que esto desaparece como realidad mínimamente compacta que pueda expresar una lógica o un escenario singular de tensiones o proyectos. Los procesos y relaciones sociales generados desde la proximidad física y los mínimos grados de autocentramiento de cualquier territorio, se pierden, por la acentuación de la interdependencia espacial lejana. En conexión con esa lectura, también se pierden posibilidades endógenas de construcción de un orden local y de formas de liderazgos y poderes locales; en definitiva, de un sistema político local (González, 2009); eso se puede describir como un descentramiento de lo local. Con la pérdida de identidad y cualidad de las relaciones de proximidad de base territorial, se pierde la existencia y necesidad de una relación directa con los otros, lo que conlleva una nueva forma de habitar, menos territorializada físicamente.

Estructuralmente, las localidades ya no se ordenarían internamente por la complementariedad de actividades, roles o funciones, sino se transforman en fragmentadas y extravertidas. Son nuevos tipos de relaciones no basadas en la proximidad física, sino que tienen la forma muy acentuada de redes hacia fuera. La expansión de las tecnologías de la información y la comunicación, posibilitan relaciones sin necesidad de vecindad, constituyéndose extensas redes que superan y trastocan las escalas y límites tradicionalmente definidos como locales, los que quedan mirando siempre "hacia afuera". Esto implica que lo local queda fuertemente ligado a estas redes de relaciones, en tanto cada vez más personas se integran a ellas, como forma de reproducirse, definiéndose un local territorial discontinuo, agrupado en torno a homogeneidad (de identidades, intereses, roles) hacia afuera y no a una proximidad en el espacio.

Lo local, se entiende desde esta perspectiva como un entrecruzamiento de múltiples redes supralocales, como un nodo de alta densidad del entramado de redes; aunque esta densidad puede variar enormemente según la posición de la localidad. La existencia de redes de relaciones implica que muchas de estas se interponen, cruzan, definiendo lo local como un espacio de cruce. Estas no están articuladas entre sí, sino que "coexisten", lo que explica la existencia, por ejemplo, de "varias ciudades en una misma ciudad" (la ciudad industrial, la de las oficinas, la economía informal), que desbordan el espacio (Bourdin, 200o). Lo local, a través de este carácter de entrecruzamiento de redes, destaca la importancia de la co-presencia más que de una

1. Nuestra propia aproximación la desarrollaremos en el capítulo siguiente, al interior de la respuesta a la pregunta por las posibilidades de desarrollos endógenos locales, en tanto ello obliga a precisar la relación entre lo local y lo supralocal tanto en términos de realidad efectiva como de proyecto posible. 
proximidad con contacto. Lo local cambia al calor de la reconfiguración de las redes, de sus decisiones de deslocalización y relocalización más amplias y, por ello, queda más como un producto o resultado, que un agente.

Otra aproximación a lo local también parte de la acentuación contemporánea de la interdependencia entre los espacios y la existencia de redes mundializadas, pero enfatizando que ellas expresan relaciones de poder y dominación que van desde arriba hacia abajo. Es decir, la interdependencia tiene la forma de relaciones desiguales y de dependencia. Por ejemplo, la producción de una cultura global, al servicio de la cual están los medios de información y comunicación mundializados va opacando, extinguiendo y transformando las expresiones más locales. Eso puede llegar a plantear la idea de un potencial genocidio cultural.

En general, un plano fuertemente destacado de esta imposición global ha sido el de la economía desde los grandes agentes (empresas) trasnacionales (De Mattos, 1994), la lógica de la globalización es avasallante y vuelve imposible toda posibilidad de desarrollo local. Cabe situar en esto la perspectiva de los "territorios corporativos" de Milton Santos, que distingue en el proceso de globalización a los agentes "globalizadores" y a los "globalizados". Este enfoque enfatiza en las transformaciones que la globalización ejerce sobre los territorios, a través de las grandes corporaciones. Partiendo de la idea de territorios usados como conjunto indisoluble, solidario y contradictorio, de sistemas de objetos y sistemas de acciones (Silveira, 2007) plantea que estas grandes compañías, en oposición, ejercen un uso corporativo del territorio. En esta concepción de globalización, los agentes corporativos intervienen en el territorio a costa de transfigurar lo local. El capital corporativo opera en alianza con los Estados nacionales, generando una "alianza perversa".

En ese sistema-territorio se insertan diversos actores que lo usan pero que son reordenados desde los intereses de las grandes empresas. La globalización, así, ejerce un peso preponderante sobre otros actores, impidiendo una regulación en función del uso democrático del espacio. Si tradicionalmente los territorios se ordenaban, en parte, de acuerdo a una interdependencia entre actores locales, llamada solidaridad orgánica, en la globalización se ordenan mediante una solidaridad corporativa, que excede los límites del territorio y funcionaliza a este.

\section{Lo local como lugar de resistencias}

Una literatura significativa, algunas veces articulada con el enfoque anterior ha llamado la atención acerca de los espacios locales como espacios de resistencia frente a agentes y proceso globalizados que generan efectos negativos en el territorio. Estos procesos y agentes globales no actúan sin oposiciones activas presentes en diversos territorios. En este caso lo global no disuelve lo local, sino que hace emerger, al menos en algunos territorios, una reacción política que realza su valor. La propia visión antes 
señalada de Milton Santos en la perspectiva de los “territorios corporativos" veía en dichos territorios las bases de la resistencia a la globalización desde los globalizados. Ello alcanza un grado máximo en planteamientos que visualiza en lo local potencialidades democráticas como una alternativa a los procesos de globalización; una suerte de "revolución antiglobal".

En este caso, lo local territorial no es solo la superposición de redes hacia afuera, ni el dominio completo de agentes y procesos globales, sino también algo constituido por relaciones horizontales simétricas y capacidades autogestionarias que se enfrentan a poderes exógenos con lógicas disolventes y funcionalizadoras, destacándose la creación de múltiples espacios en conflicto y disputa.

Una de las referencias empíricas de esta aproximación es la que ha destacado la enorme cantidad de conflictos socio ambientales en América latina el último decenio, con importante presencia de campesinos y pueblos indígenas. Ello ha hecho hablar del "giro ecoterritorial" de las luchas sociales (Leff, 2006) y del surgimiento de discursos y sentidos sobre la territorialidad (Svampa, 2008). Con ello se ha buscado representar la disputa que hay entre determinados agentes -como grandes empresas, para quienes el territorio puede ser un soporte y una fuente de recursos de lo que se puede obtener una renta- con otros, como las poblaciones locales, para las que el territorio puede ser subjetivizado como el medio de la vida y el lugar de arraigo e identidad(Svampa, 2016). Esta fuerte raigambre territorial desde la experiencia de reproducción de la vida les hace proclive a formas de defensa que hacen del territorio algo que va más allá de un solo recurso a explotar.

Este anclaje ha sido expresado como característica de las formas de organización socio-ambientales, y se expresa en el uso habitual de asambleas, un carácter auto-organizativo, con una orientación hacia la construcción de redes locales y externas del mismo tipo, y una autonomía de las expresiones tradicionales, como los partidos políticos (Svampa, 2016). Esta autora plantea que frente al modelo neoliberal extractivoexportador se levantan conflictos articulados desde un ecologismo popular (Martínez Alier, 2007), que se opone a las categorizaciones que agentes externos hacen de los territorios (eficiente/ineficiente, viable/inviable).

Es importante señalar que algunos conflictos pueden terminar en negociaciones donde aparecen medidas compensatorias o compromisos de parte de las empresas. Esto puede llevar a discusiones y divisiones entre las organizaciones por diferencias ideológicas entre sus miembros o por significados diversos que pueden tener las compensaciones. Sin embargo, también esos procesos y momentos conflictivos pueden ser la base de la emergencia de nuevas ideas para el desarrollo de la localidad, que trazan caminos de alternatividad a los existentes.

Como se ve, aquí el territorio local no se disuelve, sino por el contrario puede fortalecer su identidad a través del conflicto y la lucha. Aparecerían respuestas vincu- 
ladas a las reivindicaciones de las identidades culturales primarias. Así, "la desterritorialización provoca nuevas territorializaciones culturales" (Bolivar, 2001, p. 265). En este sentido, aparece interesante de mencionar la idea de "lugarización", de González (2009) si la palabra globalización quiere significar todos los procesos que hacen de todo el planeta un solo espacio, la palabra lugarización quiere significar todos los procesos que revalorizan lo local.

\section{Lo local como lugar para construir competitividad e inserción global}

Otro enfoque, muy influyente en algunos lugares, ha puesto el acento en lo decisivo de la naturaleza y calidad de los territorios para su inserción exitosa en una economía globalizada, a la cual no se puede eludir. Así, Quintero y Gallardo (2008) entienden el desarrollo local como una forma de actuar desde lo local para insertarse en el sistema global de forma competitiva. Lo global se presenta como un desafío obligado a lo local; pero a la vez, la inserción en lo global necesita afirmar lo local. La globalización es tomada, entonces, como una oportunidad de integración económica e impone mejores condiciones para el desarrollo de lo local (Vázquez-Barquero, 200o). De acuerdo a Boisier (2005), la globalización implica una revalorización del territorio. Los sujetos no son "ciudadanos del mundo", se encuentran siempre desde lo local. La segmentación territorial de la producción, gracias a las Tecnologías de la Información y Comunicación (TIC), necesita mirar y entender los territorios para ser exitosa. Las identidades locales no necesariamente desaparecen frente a la cultura global, coexisten, y se hacen necesarias para integrarse en lo global. La entrada en la globalización necesita, para insertarse con éxito, afirmar las identidades desde las cuales se enfrenta lo global.

A la vez, la inserción en lo global no es solamente asunto de las empresas, sino tiene que ver con la calidad del territorio en donde aquellas están insertas; su competitividad es, finalmente, la competitividad de los territorios, en los cuales podrá haber (o no) capital humano, cooperación entre las empresas, iniciativas público privadas, creación de saber, identidad, capacidades institucionales para articular actores, etc. En este marco, se establece que la globalización -en el campo de las actividades que requieren economías de la diferenciación, "favorece la pequeña escala, la producción flexible y en red, la localización múltiple y el anclaje territorial” (Boisier, 2005, p. 52), todo lo cual platea oportunidades y desafíos a estrategias locales.

Los propios procesos y agentes globales ya no dependen tanto de sus coherencias o sinergias internas, sino de la adecuación a los territorios y economías locales donde buscan localizarse para poder ajustarse al escenario de competencia global creciente, poniendo como eje principal el proceso de acumulación de capital que impone la globalización en los territorios. Así, desde esta perspectiva, la globalización se presenta como un fenómeno que, en vez de minimizar el papel de lo local, lo rescata. Frente a 
la apertura abrupta de los mercados, posibilitada por las políticas macroeconómicas y las innovaciones socio-técnicas, los territorios locales tienen la oportunidad de volcar sus estrategias de producción y desarrollo a mejorar su condición de competitividad. Como señala Bervejillo (1996), por un lado, la globalización "amenaza a las viejas unidades territoriales, países, regiones o ciudades, con inducir la fragmentación, el desmembramiento, la desintegración económica y social" ( p. 39), pero por otro representa una oportunidad, ya que "permite a los territorios un acceso más abierto a recursos y oportunidades globales, la valorización de recursos endógenos latentes y el acceso o formación de redes interterritorios".

Una variante de esta aproximación, pero que muestra facetas más ambiguas y complejas, es la generada desde la experiencia de los "distritos industriales", donde se combinan apertura y centramiento, competencia y cooperación. Estas experiencias alcanzaron un auge en Italia, y representaron una "entidad socioterritorial (que) se caracteriza por la presencia activa tanto de una comunidad de personas como de un conjunto de empresas en una zona natural e históricamente determinada" (Becattini, 1989). Representan una combinación entre un tejido denso de pequeñas y medianas empresas locales (Schiliró, 2008) que muestran un tipo muy activo de comportamiento competitivo por parte de sus individuos, con una cooperación semiconsciente y semivoluntaria entre ellos (Becattini, 1989), pero también vinculado hacia un mercado de escala global. La especialización del distrito consiste en empresas que pertenecen al mismo sector industrial, incluyendo a las "industrias auxiliares". Se enfatiza, también, que existe una comunidad local constituida por una comunidad de personas con un sistema homogéneo de valores.

El distrito tiene en sus lecturas quienes resaltan más el carácter de sistema productivo local capaz de resistir, y en cierto grado obligar a adaptarse, a las grandes empresas globales. En este sentido recoge y expresa visiones con algunos grados críticos a la globalización, aunque no con la orientación de la desconexión con ella. De acuerdo a estas lecturas, experiencias de este tipo en los países del sur de Europa (Italia, Francia, España y Portugal) son concebidas como alternativa al modelo de la gran empresa vertical y comprende una nueva corriente teórico-interpretativa impulsada directamente por las pequeñas empresas, instituciones y actores locales que se convertían en los agentes principales de los proyectos de desarrollo (Garofoli, 1992, 2002; Vázquez Barquero, 2005).

Pero también el distrito ha sido leído y valorizado por las condiciones que crea para acceder hacia el mercado global. Aquí, la centralidad del territorio y de la comunidad que lo constituye (considerando también el tejido empresarial), se une a la necesidad de conectar la producción local con un mercado de escala mayor. Esto, a pesar de que las empresas del distrito nacen, se desarrollan y mueren quedándose generalmente al interior del distrito (Lorenzoni, 1983). 
En esa perspectiva crítica, pero desde una mirada más allá de los distritos, hay quienes enfatizarán que, finalmente, las localidades quedan determinadas por un proceso global de diferenciación espacial desigual que va asignando roles, desde una división geográfica de la producción y el trabajo, y que, por ello, va determinando territorios ganadores y perdedores (Albagli, 1998).

Podríamos decir que en el distrito industrial hay valoración del territorio por la capacidad de generar un tejido "hacia adentro" lleno de relaciones, que abarcan lo identitario-cultural y la confianza, así como la socialidad y las instituciones locales, y es eso lo que para muchos representa el aspecto relevante; pero también, a partir de lo anterior, la capacidad de proyectarse hacia el mercado global con éxito, un desarrollo "hacia afuera", lo que resulta central, para otras visiones.

\section{La aproximación desde la mezcla y la hibridación}

Una última aproximación que podemos detectar como parte del importante efecto de procesos mundiales sobre las localidades, destaca la existencia de una cierta fuerza cultural de los territorios, que impide un fenómeno de puro desplazamiento de lo local, como algo propio, sea bajo la forma de su disolución o bajo la forma de dependencia y determinismo estructural, a un orden mundial. En este sentido, lo local territorial no son papeles en blanco (territorialidades vacías) donde se escribe lo que llega desde afuera, arriba o los lados. Tampoco es impermeable a las acciones y procesos de mayor escala y globales y que ejercen influencia en sus planos simbólicos y materiales .

Lo que se produce, es un encuentro que genera reapropiaciones por las sociedades locales de los flujos materiales y simbólicos que provienen desde agentes y espacios que se dirigen a la escala global. Eso va produciendo síntesis y haciendo emerger nuevos elementos y representaciones que ha sido expresada como la realidad de la "glocalización". En el ya clásico artículo de Robertson "Glocalización: tiempo-espacio y homogeneidad" (200o) se describe esa realidad como una resultante de los tiempos de globalización que no disuelve lo local pero que sí lo transforma.

Para Bolívar (2001), la glocalización se refiere a la mezcla que, en términos culturales, se da entre los elementos locales y particulares con los mundializados. Señala, al respecto que, justamente, "una parte de los análisis sociales se ha orientado a ver cómo las fuerzas globales interactúan con las culturas locales, las que también impregnan a las corrientes globalizadoras. Esto suele expresarse, también, como que estas últimas son mediadas y filtradas por las culturas locales, produciendo configuraciones particulares, construyéndose la realidad del glocalismo" ( p. 5).

Esto, también, ha sido leído desde la noción de culturas hibridas, en que van emergiendo combinaciones de tiempos y espacios y se van configurando hibrideces que pueden significar particularidades territoriales (García Canclini, 1990). Estas hibri- 
deces, sin embargo, no debiesen ser significadas como faltas de poder de algunos intereses o representaciones sobre otros o de la existencia de ciertas heterogeneidades materiales y culturales en un mismo territorio.

\section{Ideas, condiciones, desafíos de una propuesta de desarrollo local endógeno}

En el marco de la historia de cómo los territorios locales han sido vistos, incorporados, considerados o proyectados con el propósito del desarrollo, la exploración que realiza este capítulo es acerca de cómo las sociedades locales pueden adquirir un alto protagonismo para ese propósito. Esto no lo planteamos en términos solo de racionalidad instrumental -es decir como un medio para ser más eficaz- sino de manera más fundamental, como componente de una forma de entender el desarrollo que tiene características propias y críticas, que ha presentado no solo bajo el neoliberalismo, sino también a otras formas desarrollistas anteriores. Esto significa la concepción de la economía al servicio del desarrollo integral de las personas y los pueblos, poniendo en cuestión una visión ideológica de la necesidad de ampliación permanente del capital. Significa, también, una idea de desarrollo o de futuro a partir de la consideración de las características culturales propias, como es el caso de comunidades indígenas que expresan la existencia de alternativas respetuosas a las formas de entender una buena vida (Hernández y Vargas, 2015). Asimismo, la endogeneidad local recoge la perspectiva de una economía a "escala humana" buscada en planteamientos como los de E.F. Shumacher en "Lo Pequeño es Hermoso" (1984) y de Max Neef, Elizalde y Hopenhaym en "Desarrollo a Escala Humana" (1986). Debe combinar la capacidad de adaptación creativa a fenómenos generales, con la capacidad de tener estrategias de acción activa para ir construyendo las realidades locales aspiradas.

Es importante, sí, aclarar, que esta perspectiva alternativa de un proceso local con protagonismo endógeno, se concreta integralmente cuando la orientación que tenga una trayectoria con esas características presenta, a la vez, ribetes democráticos, ecológicos, igualitarios, lo que no está automáticamente asegurado por el carácter de endogeneidad local. Esto permitiría reconocer que podemos tener distintos "estilos" de desarrollo local endógeno.

El tipo de preguntas que acompañan esta exploración son: ¿qué capacidad presentan o pueden presentar los territorios locales para enfrentar sus problemas y para dirigir un proyecto con cierta autonomía? ¿tienen márgenes para ser protagonistas de proyectos de sustentabilidad local endógena?; ¿cómo empujar un proyecto de desarrollo local en un escenario que se presenta difuso, dinámico y desarraigado? En definitiva, ¿es posible el desarrollo local endógeno en tiempos de globalización?; ¿un desarrollo orientado por agentes y factores territoriales locales? $\mathrm{O}$, ¿qué condiciones debiesen existir o ser creadas para esa posibilidad? 
Una primera afirmación en los preámbulos a una respuesta es que necesitamos asumir que ello no debe eludir la complejidad que comprende. Afirmaciones como la necesidad de un aprovechamiento del potencial endógeno, tanto material como cultural, del fortalecimiento del capital social a través de redes múltiples y de una alta participación local y un buen gobierno local (Tolón y Lastra, 2009), suponen muchos aspectos en juego.

Esta complejidad, además, debe superar la antinomia local-global, dada la complejidad de las dinámicas socio-económicas actuales, redefiniendo formas de articulación asimétricas dentro de una cierta integración al interior de una tensión permanente. Aunque Boisier (2005) señale que por definición el desarrollo siempre es local, es decir territorialmente focalizado - según plantea también Perroux (1964)- y, por tanto, esencialmente endógeno, descentralizado, capilar, dependiente de la trayectoria e históricamente evolutivo, ello es en un sentido de movimiento material de la sociedad, pero no desde el punto de vista de los agentes, escalas y niveles en que se toman decisiones que llevan a ese movimiento material, a ras de suelo. Por ello, lo endógeno supone ese acercamiento o proximidad entre dicho movimiento y los agentes, escalas y niveles de la realidad desde los cuales se incide protagónicamente. Sino aquel movimiento o dinámica local puede tener un origen exógeno, aunque se exprese materialmente en espacios locales.

\section{La cuestión de la escala}

Una pregunta que pareciera necesaria despejar es cuál es la escala del o para el desarrollo endógeno. En cierto grado en esa pregunta suelen estar presentes dos dudas acerca de la viabilidad de un proceso de desarrollo local endógeno. La primera, es que un territorio muy pequeño no puede ser pensado con capacidades o recursos endógenos mínimos para auto-impulsarse. La segunda, es que uno muy grande podría imposibilitar la gestión democrática del territorio, en particular cuando la pensamos con una participación más directa de parte de sus habitantes.

Nuestro punto de partida conceptual es que entendemos "lo local" como una escala de lo social (Arocena, 2002) sin asociar ello con una territorialidad específica. Podemos decir que hablamos de territorialidades que son sub-nacionales y tienen en las dimensiones y realidades regionales sus expresiones mayores. Hablamos, entonces, de desarrollo local en referencia a cualquier escala social igual o menor que las regiones en la medida que puedan autogenerar e incidir con grados de importancia en las condiciones de vida determinadas que tienen sus habitantes; espacios en los cuales puedan existir intra-relaciones y auto-impulsos que tienen orientaciones hacia abajo, hacia arriba y hacia los lados; que pueda generar densificación de lazos internos y sinergias positivas entre sus actividades. 
En términos físicos absolutos y relativos ello no se refiere a una escalaridad fijada ni fija. Esa escala puede transformarse en el mismo proceso en tanto espacio que polariza un conjunto amplio de relaciones. A la vez, pueden existir desarrollos locales envolventes y envueltos dado que una escala local puede presentar un proceso interno de cambio hacia mejores condiciones de vida y de relación con la naturaleza y, a la vez, ser parte de otra escalaridad mayor, pero aun local, que tiene su dinámica propia y más agregada que envuelve y tiene relaciones con la primera. Lo local, desde nuestra perspectiva debe entenderse como un "complejo de locales" que pueden tener relaciones entre sí, de sinergias, tensiones o de "envoltura".

Ha habido autores que le han dado a cierta escala, pero asociada a algunas características, cierta primacía para pensar en desarrollos locales. Por ejemplo, Vázquez Barquero (2005), plantea que el escenario predilecto para dinámicas de ese tipo son las ciudades intermedias. Sin embargo, se podría decir que toda espacialidad local puede tener potencialidades de desarrollo local, aunque las formas en que ello pueda ocurrir sean muy diferentes. Si aceptamos esto, al menos en principio, podemos identificar, sin ánimo exhaustivo, varios tipos de "locales" que pueden ser sujetos de procesos de desarrollo: zonas rurales, ciudades intermedias, áreas metropolitanas, regiones o ciudades intermedias, ciudades portuarias, espacios transfronterizos, zonas populares de grandes ciudades, etc., constituyen espacios con algún grado de densidad social, en los que inciden o pueden incidir, con distinto poder y ascendencia, los múltiples agentes (del desarrollo). Aún más, cada una de esos tipos de territorios locales, puede presentar varias distinciones en su interior (González, 2008a).

Una escala local de acción y mejoramiento no tiene por qué ser definida por una delimitación político-administrativa del Estado; aunque también puede haber correspondencia con alguna de ellas. Por un lado, podemos afirmar que las territorialidades locales que se van constituyendo o desconstituyendo en la dinámica social no necesariamente corresponden con la estructura con que el Estado se zonifica en el espacio nacional a partir de sus estructuras territoriales descentralizadas y desconcentradas, pues los territorios vividos se sobreponen a algunos de los límites administrativos o referencias materiales del espacio, y su gestión se presenta como un desafío frente a este tipo de movilidad.

Pero, por otro lado, una zonificación establecida puede ejercer efectos en que la dinámica social se organice en torno a aquella delimitación realizada por el Estado. El surgimiento de esta última, además, puede ser el resultado de una dinámica social que justificó esa delimitación local en lo político administrativo, como el surgimiento de una región (por ejemplo, la reciente constitución de la Región de Nuble, en Chile), provincia o comuna. Por todo esto, en la medida que el Estado tiene la capacidad de operar a distintas escalas, y en diferentes ámbitos, es un factor de producción de territorialidades, pero a la vez, no las define exclusiva ni completamente y puede ser 
configurado por ellas. Y, por cierto, existe también la posibilidad de innovar en términos de escala, como en el caso los Comprensorios o Comunidades comprensariales italianas, unidades administrativas que agrupan diversas comunas y que permiten la coordinación de los municipios en lo concerniente a los servicios sanitarios, la cultura, la economía y la ecología.

La definición de las escalas de análisis y acción es algo que tiene mucho de resultante de procesos históricos, pero a la vez puede ser un ejercicio también consciente de parte de agentes que concluyen la importancia de determinar algunas, aunque, como vimos, no pueden ser tomadas como excluyentes sino también pueden ser envolventes. Un ejemplo interesante, que tiene un soporte analítico y a la vez indicativo para la acción es la noción de "agropolis", que visibiliza la existencia de una cierta territorialidad continua entre ciertas ciudades y su entorno más rural, no como dos espacios separados sino imbricados en que se combinan lo urbano con lo rural en toda su realidad (Canales y Hernández, 2011; Canales y Canales, 2012; Friedmann, 1996), y que se puede encontrar en zonas como el valle central Maulino, en Chile. Interesante de mencionar puede ser también el ejemplo, más acotado, del cinturón de Lieja (Bégica), donde la articulación de diversos actores locales para un proyecto de abastecimiento local de producción agrícola hacia la ciudad desde su periferia rural, permite la construcción de nuevas territorialidades.

En términos históricos, las escalas de referencia locales, en la medida que comprenden a la esfera económica y son influidas por la acción de agentes privados, pueden tender a ampliarse como producto del proceso de división del trabajo y de intercambio, a mayores distancias. Podemos hablar de un ensanchamiento de los diversos componentes que hacen parte relevante de esa esfera, como, por ejemplo, lo que pudiésemos llamar "áreas locales de empleo". Estas se definen como el área en que se busca y se tiene trabajo/empleo sin tener que cambiar de residencia por razones de distancia. Esta área ha aumentado, principalmente por avances en la densidad vial y la velocidad del transporte. Esto implica que, en ciudades grandes, crece el número de personas que viven en una zona y se desplazan, a veces largos trayectos, a otra para trabajar. Este proceso lleva a una ampliación de la territorialidad individual, al territorio vivido, al "espacio vital" cotidiano. De todos modos, la expansión de los puntos de referencia se evidencia en casi todos los ámbitos de la vida social, como por ejemplo a través del desplazamiento vehicular, que se presenta como una necesidad para vincular los diferentes puntos de referencia, lejanos entre sí, no necesariamente contenidos en una única proximidad y que recorremos normalmente. Dichos puntos componen "sub-territorios" diferenciados, y medios de comunicación y movilidad que los unen. En esa práctica se define una experiencia de moverse en un espacio local que es más amplio y menos intenso, a la vez. Se da origen a un macro espacio 
local que se compone de micro espacios locales que se revelan como tipos de escalas distintos, constituyendo potenciales agentes y objetos para la intervención local, con influjos múltiples.

Según esto, podría haber una brecha entre el territorio experimentado en la vida cotidiana, en constante crecimiento y cambio, y la escala del territorio sobre el cual existe una capacidad de gestionarse democráticamente por los sujetos y en que pueden existir muchas ciudades en una misma ciudad (Bourdin, 2000).

La acción local no puede plantearse como referida solo a la escala correspondiente pues la escala local no se presenta aislada de otras. Se deben entender y asumir de manera dinámica e interdependiente. Muchas preocupaciones locales se han vuelto globales y viceversa. Existen cuestiones ineludibles para cualquier modelo de desarrollo que pretenda generar una transformación a la escala que sea. Son problemáticas que han tomado la característica que se expresan en todas las escalas de la vida social, pero que en lo local adquieren expresiones diferentes.

Por ejemplo, es innegable que los impactos ambientales y desequilibrios ecológicos se han instalado como fenómeno y debate permanente y que tanto los Estados nacionales como los organismos internacionales desarrollan estrategias para enfrentarlos, obviamente, dentro de los paradigmas, condiciones e intereses, que los configuran. No obstante, al nivel local esos problemas toman ribetes diversos, donde los actores locales enfrentan muchas veces la sustentabilidad como un asunto de urgencia y sobrevivencia, sin consideración de lo cual sería imposible pensar una trayectoria de desarrollo local. Por lo mismo, la cuestión ecológica se ha vuelto fundamental para el desarrollo local endógeno (Sotelo y Sotelo, 2013). El carácter local endógeno del desarrollo obliga a que los actores locales aborden los desafíos ecológicos que les impone el territorio y sus relaciones sociales, dándoles soluciones mediante estrategias. Pero ello no niega que las eficacias de esas acciones estén en correspondencia con lo que se hace desde otras escalas y agentes, haciendo de esto último una necesidad de reflexión y propuesta permanente. De esta forma, se abre todo un espacio de acción local para transformar las condiciones territoriales que supone la consideración de otras escalas. Esto se refuerza en contextos de altas desigualdades territoriales, donde las tareas del desarrollo local afectan directamente los modos de vida de comunidades desfavorecidas.

En suma, hay muchas escalas de territorios locales, las que no son fijas ni fijadas, en que todas pueden ser sujetos, en relaciones de sinergia y envoltura. Evidentemente, la escala y acumulación de capacidades, recursos y voluntades, definen la cobertura y profundidad de eventuales procesos de desarrollo y cambio, local. 


\section{La producción social del territorio}

Lo anterior, relativo a la escala, permite introducir una segunda idea gruesa respecto de un planteamiento de desarrollo local endógeno. Esta es que el territorio es una producción social; que los agentes producen lo local actuando desde diversas escalas de la realidad y desde diferentes tipos de relaciones entre ellos, ya sea de oposición, negociación o cooperación. (González, 2008a). Podemos reforzar la idea que lo local, como una escala de lo social, no está simplemente dado, sino que existe una construcción social de lo local. No es solo un espacio de interacción, compuesto de múltiples relaciones sociales, sino, a la vez, el resultado de esas interacciones.

Esta producción social de lo local desde agentes determinados, configura sociedades locales. De allí, podemos decir que el desarrollo local endógeno necesita de una sociedad local fortalecida, donde exista un entramado complejo de relaciones entre actores que constituyan un escenario capaz de propiciar la endogeneidad desde un territorio. Esto lleva a la necesidad de precisar agentes que puedan protagonizar procesos de dinamización, de cambio, de transformación, de preservación, etc. en la localidad.

En primer lugar, se necesita un proyecto de desarrollo endógeno, que incluya como protagonistas a los actores locales ${ }^{2}$ como gestores y beneficiarios del desarrollo. Esto puede parecer una tautología o redundancia; pero no lo es pues algo propio de la fuerte interdependencia asimétrica que define a la globalización es que la reproducción de las sociedades locales está fuertemente producida por y desde agentes no locales y, muchas veces, globales. Podemos decir que la importancia del rol que asumen los actores locales debe ser un modo de compensar los efectos de la envoltura globalizadora a través del mercado y de empujar una dinámica socio-económica propia.

Lo global, entonces, no es "un entorno de lo local" y que impone ciertos límites o cotas dentro de los cuales lo local se mueve. Más que eso, es una escala de la acción de agentes que, con sus decisiones y acciones, son constructores de los territorios locales. De ello, se puede deducir que afirmar procesos locales con protagonismo de actores locales no es algo banal en tanto ellos son solo uno de los tipos de agentes que intervienen en la construcción de lo local. Su peso relativo mayor es lo que permite hablar de procesos endógenos o neo-endógenos (Ward et al., 2005).

Cabe destacar, de todos modos, que en estos procesos de dinamización pueden tener roles protagónicos también ciertos actores externos -si es que son guiados por ciertos principios democrácticos- como en el caso del Programa Leader de la Unión Europea, que promueve la conformación de Grupos de Acción Local, estructuras con alta participación de los actores locales para la promoción del desarrollo territorial.

2. Definimos agentes locales a quienes habitan la sociedad local, trabajan allí, y proyectan su futuro dentro de aquella. 
De acuerdo a los agentes locales involucrados, suelen haber menciones que tienen como referencia tipos de territorios locales, así como enfoques determinados sobre el desarrollo local endógeno. Tradicionalmente, por ejemplo, desde el desarrollo local que enfatiza lo económico se consideraba como actores fundamentales a las empresas locales, capaces de producir riqueza y valor. En otros casos se da enorme importancia a los actores institucionales como los municipios. También, en ciertos enfoques aparecen relevadas las organizaciones de la sociedad civil (local) y en ciertos momentos, procesos y localidades, agencias nacionales o internacionales no gubernamentales ya sea más técnicas o más animadoras de procesos sociales participativos.

Algo relativamente corriente es asociar la posibilidad de desarrollo local endógeno con la participación de diversos actores locales, los cuales tienen diferentes identidades, intereses y medios. Aquí, se enfatiza la importancia de un agente "compuesto" expresado como articulaciones o coaliciones por el desarrollo local. Estos actores y entramado de actores son diferentes según las distintas sociedades locales y dependen de sus estructuras productivas, de su geografía, de sus tradiciones culturales, del surgimiento de nuevos grupos sociales, etc.

\section{Hacia un poder democrático y descentralizado}

De lo expuesto anteriormente podemos concluir que la sociedad local se constituye en base a una densidad socio-política de las relaciones entre actores que constituyen, en ese proceso, al territorio. Lo local se teje como un espacio donde se toman decisiones y se ejerce el poder en diferentes direcciones y sentidos. De esta forma convierten lo local en una escala de lo social, no solo como espacio de socialidad sino también como espacio de ciudadanía. Es desde este entramado de relaciones que se constituye una dinámica determinada de desarrollo local que podrá contrastarse con los juicios normativos que tengamos de este.

Esa escena y dinámica local, puede presentar varias formas; puede existir, reproducirse o cambiar según distintas configuraciones de poder. Así, por ejemplo, la sociedad local puede estar ligada al dominio de ciertas elites y la acción guiada por el peso de los "notables". Eso puede también enunciarse como un poder local concentrado y oligárquico, lo que reconoce que el mapa de actores es desigual en poder y riqueza, y en que lo local puede reproducir esa inequidad. Pero también el espacio local ha solido ser la representación de la democracia radical. Es decir, de lo local como ámbito de la horizontalidad y la participación más directa y que es lo que alienta y encarna la perspectiva endógena.

Esta perspectiva de fortalecimiento de poder local, debe ir acompañada por una creciente democratización de la sociedad, haciendo de ese mayor poder una democratización efectiva, tanto en las instituciones como dentro de la sociedad civil, considerando a los grupos subalternos que han sido marginados del desarrollo. Supone 
actores que le den valor político a los espacios locales, la existencia de entidades y modalidades que permitan la deliberación y decidir como foros, consejos, comités, plebiscitos, construcción de planes, etc. (Franco y Gómez, 2004). Un ejemplo claro de aquello son las experiencias emblemáticas de los presupuestos participativos en ciudades de Brasil como Curitiba y Porto Alegre, que integraron a la población a decidir cierta parte del gasto municipal.

Un modelo de desarrollo local y democrático a la vez, entonces, necesita disminuir la desigualdad de poder. Este propósito debe entenderse no como un eventual acompañamiento del proceso de desarrollo sino como un atributo, como parte de su carácter o estilo. De este modo, nos parece que el fortalecimiento del capital social -que concebimos como el conjunto de valores, normas y entendimientos comunes que estructuran la red de relaciones entre los actores, fomentando la colaboración y cooperación para lograr objetivos compartidos de desarrollo local (Pisani y Micheletti, 2018)- es una condición básica del desarrollo local pero que, a la vez, debe estar marcado por el aumento del peso de los sectores más subalternos. La participación de la mayoría social local y su incidencia en el sistema decisional obliga a concebir una planeación formal junto con la participación comunitaria.

Por otro lado, un desarrollo endógeno tiene como condición, pero también como indicador y como objetivo, la existencia de procesos estatales de descentralización. Sin ello, las fuerzas o movimientos descentralizadores chocarán con estructuras estatales que constituirán barreras. De ahí, la importancia del fortalecimiento político y gestionario de los gobiernos locales (en las distintas escalas de lo local que hemos antes señalado).

En la perspectiva de estructuras y gestiones estatales de ese tipo pueden destacarse dos orientaciones y funciones que hay que entender como necesarias y, a la vez, en tensión. En primer lugar, se debe tratar de" Estados locales" que asuman un rol de facilitación de procesos, más que de adoptar una posición hegemónica de experto único, lo que significa en cierto grado un cambio paradigmático en como el Estado concibe su rol con la sociedad y con las expresiones de la sociedad civil. En algunos casos ello se ha entendido como parte de una nueva gestión pública, que permita que los actores sociales sean interlocutores permanentes, corresponsables y coparticipes de la acción pública y que, por ello, le conceden más fuerza y legitimidad a la acción gubernamental. Esto debe dar pasos más avanzados a través del reconocimiento que las personas y las organizaciones o comunidades locales que poseen conocimientos y capacidades para actuar en lo público.

Pero, también, el Estado debe fortalecer una cierta lógica planificadora, que va más allá de la mera ejecución de muchas acciones que tienen poca integración entre ellas y van surgiendo reactivamente a los problemas que se van presentando. Esto significa revalorizar, bajo ciertas condiciones que sean consistentes con la idea an- 
terior, el desarrollo y ejercicio de dicha capacidad planificadora. Significa enfrentar las tendencias impulsadas en los últimos tiempos acerca de la constitución de un Estado, que incluye sus niveles más locales, de constituir un ente disminuido en su capacidad de ayudar a la construcción de visiones estratégicas y jugar papeles activos en procesos políticos de cambio. Esto, no solamente debido a la complejidad evidente de la tarea, sino también por verse supeditado a los intereses de los actores privados (nacionales y transnacionales) que regulan el mercado y que limitan sus roles a lo que les es funcional.

Un desarrollo local endógeno debe ir de la mano, entonces, de una propuesta de fortalecimiento de gobiernos regionales, provinciales y municipales, según los países, que, por ello, deben ser bastante más que la prolongación "hacia abajo" de los gobiernos centrales; que mero compensador de ciertos problemas sociales locales; y que creador de condiciones para atraer capital. Como dice Ospina (2001), desde una perspectiva municipalista, los administradores locales deben ser concebidos como agentes históricos que puedan reemplazar el proyecto globalizador por uno de desarrollo territorializado, endógeno, multidimensional, concertado, participativo, equitativo, y ecológicamente sostenible (p. 14). Se trata de una propuesta municipalista.

\section{Cooperación, conflicto y coaliciones}

Introducida la cuestión de los agentes locales y no locales como constituyentes de una escena y dinámica sociopolítica local, debe plantearse la cuestión de la cooperación y el conflicto local. Sin duda la primacía de la cooperación es un factor para que la localidad pueda avanzar en generar mejores condiciones de vida. Pero ello no nace simplemente de un puro discurso ni es un dato desde el cual se parta. Justamente, una pregunta central es la de la implicancia que para una idea de desarrollo endógeno sustentable tiene el hecho que las sociedades locales están pobladas de actores locales que pueden tener fragmentaciones entre sí, fuertes conflictos/disputas, así como también realidades o potencialidades de cooperación.

Hay casos en que ciertas dinámicas territoriales han sido caracterizadas como virtuosas justamente por la existencia de importantes grados de cooperación. En el caso de los distritos italianos, por ejemplo, fueron entendidos como una entidad socioterritorial caracterizada por la presencia activa de un sentido de comunidad y de un conjunto de empresas con fuertes tejidos socio-económicos, en una zona determinada. Según lo detectado por los análisis, como resultado de factores históricos y culturales por un lado, y técnicos-económicos por otro, los actores se articulan por una relación permanente entre cooperación y competencia (Becattini, 1989). Eso no eliminaba la competencia, pero esta ocurría en un ethos y atmosfera que favorecía la cooperación. 
Esta "comunidad local" puede también configurarse a partir de una realidad de desmedro común y generalizada, como en principio presentan las llamadas "zonas de sacrificio" caracterizadas por concentrar actividades que significan agresiones medio-ambientales de variado tipo y que son, a la vez, depositarios de desechos de actividades desarrolladas en otros territorios. Es decir, se produce un territorio de cooperación desde su condición de "sacrificados comunes". Sin embargo, esto suele ser más complejo pues, a pesar de esa realidad común, puede haber grupos mucho más afectados que otros, y grupos que pueden aprovechar aspectos de esa situación, como el caso del comercio a partir de los vertederos, en lo que se ha llamado la economía de la basura. Divisiones que pueden ser fortalecidas por agentes que buscan que no haya una comunidad local unificada en resistencia de un megaproyecto.

Yendo al punto que aparece más complejo: en los casos que la disputa y conflicto es predominante y que está asentado sobre factores duros o radicales: ¿cómo generar condiciones para un desarrollo endógeno para el cual la cooperación local es importante?

En primer lugar, es necesario afirmar que en estos casos la problemática no debe ser vista como un impedimento para el desarrollo, sino que constituye una dimensión clave de él y que la forma y orientación en que el conflicto se resuelva o tome curso -incluyendo su mayor intensificación- constituirá una base de la forma que tomará el desarrollo de ese territorio. Es decir, en la dialéctica de esa conflictividad se estarán generando mejores o peores condiciones para una cooperación; pero ello no será el simple resultado de un llamado a la cooperación sino de que se resuelvan en alguna dirección, aceptable por la mayoría, las situaciones que dan base a las contradicciones.

$\mathrm{Al}$ respecto, una literatura importante del último tiempo ha insistido en la relación fuertemente conflictiva en territorios locales como la que plantea que frente a los efectos del poder corporativo de las grandes empresas han surgido movimientos de resistencia en localidades con presencia de aquellas. El territorio aparece y se constituye como escenario de disputa de "modelos de desarrollo" en que por un lado está el gran capital, a veces transnacional, de carácter extractivista, que "usa" el territorio y lo codifica según su rentabilidad, y, por otro lado, están organizaciones socio-ambientales que le conceden una centralidad al territorio como su elemento constitutivo, y que combinan la acción directa con la acción institucional, la democracia asamblearia, la autonomía y la multiescalaridad de la acción (Svampa, 2008). Inclusive, ciertas corrientes del feminismo comunitario y del eco-feminismo, llegan a plantear una conexión entre el territorio y el cuerpo, como en el caso planteado por Capnal (2010), que destaca la resistencia de las mujeres xinkas de Guatemala en la defensa de su tierra contra la minería, al mismo tiempo que emprenden la liberación de su territorio-cuerpo rebelándose a las formas patriarcales y capitalistas de opresión a la mujer. 
Particularmente importante en América del Sur, en las últimas décadas, es la generación de "zonas de sacrificio" vinculadas a procesos de neo-extractivismo expansión de las fronteras de explotación hacia territorios que antes se consideraban marginales, basados en la sobreexplotación de los recursos naturales, el agronegocio y de la proliferación de monocultivos transgénicos (Biocca, 2020), que tienden a transformarse en focos de conflicto de alta intensidad.

Pero existen también conflictos de tipo más débil o "intermedio", pero reales e igualmente significativos en la dinámica local. Por ejemplo, al interior de grupos medios locales puede haber capas más globalizadas o globalizantes y capas más identitarias o localistas; grupos más privatistas o más partidarios de un protagonismo estatal (González, 2008b).

Estos antecedentes conducen a asociar las posibilidades de desarrollo endógeno con la creación de un cierto "agente compuesto" que es una coalición amplia. Aunque este no ha sido un tema muy debatido, a menudo, aunque con distintas denominaciones, se deja entender la importancia de que haya existido una articulación o concertación de actores locales en algún proceso local o, a la vez, se suele afirmar que su ausencia suele ser la mayor barrera para la generación de un proceso tal (González y Calderón, 2018). Una coalición significa grados de reunión, coordinación y planificación entre diferentes agentes actuantes en el territorio; asimismo, grados de convocatoria, animación y acción. Ello, encarnando una determinada orientación y concreción de DLE y construyendo una identidad "hacia delante" al territorio local.

En formulaciones genéricas, se suele entender estas coaliciones en términos de una relación o concertación entre lo público y lo privado empresarial, aunque aquí también pueden expresarse otras formas de propiedad y gestión como cooperativas o empresas solidarias. A veces, también, se considera una tercera categoría -que es lo social- integrada por distintas entidades de la sociedad civil. Siendo válido ello, a un cierto nivel de abstracción, lo señalado sobre la cantidad y variedad de agentes que producen lo local, dichos enunciados, pueden adolecer de grados de simplificación al no distinguir las diferencias cualitativas que suele haber en lo privado - por ejemplo entre microempresas y filiales de empresas trasnacionales- en lo social -por ejemplo entre sindicatos, ONG's, organizaciones campesinas y rurales, Iglesias o medios de comunicación- y en lo público - por ejemplo, entre entidades territoriales o entidades sectoriales del Estado. Dicha distinción básica anterior suele, además, desconocer la existencia de lo público no estatal y lo privado con fines públicos y sin fines de lucro. Por lo tanto, la cuestión de las coaliciones plantea el tema de la diversidad de agentes, en quienes se reconoce una diversidad de orígenes, visiones e intereses, los que expresan la complejidad de la sociedad local y de su producción como tal. 


\section{El lugar de la identidad y la cultura local}

La cuestión inicial es establecer la relación existente entre identidad local y desarrollo endógeno. Desde ahí es posible avanzar, entendiendo cómo se construye o fortalece esa identidad en los territorios. También aquí se plantea la pregunta por la posibilidad de identidad si se parte de la existencia de expresiones diversas en el territorio local y, aun, de territorios con fuertes conflictos.

De acuerdo a nuestro punto de vista, el papel que juega la identidad en los procesos de desarrollo local es fundamental, lo que en general suele ser reconocido. En algunas experiencias que han sido catalogadas de exitosas, la identidad ha sido considerada una dimensión y factor clave (Arocena y Marsiglia, 2018).

Pero ello no debe ser entendido en un sentido instrumental o en el solo plano de la eficacia. Pensamos por ejemplos en casos históricos como el de Lota, en Chile, con una fuerte identidad vinculada a la actividad extractiva del carbón, y que sin embargo se encuentra hoy con índices sociales y económicos muy deficientes. La identidad local, normalmente asociada a rasgos culturales, debe ser planteada como base para un desarrollo local que reconoce o expresa las singularidades. Con esto se funda la idea de "desarrollos locales", que expresan esas singularidades, y la no existencia de "un" desarrollo universal. (Arocena, 2002; González, 2012). Se puede mencionar aquí la experiencia de Villa El Salvador, en la ciudad de Lima (Perú), donde se crea un proceso de carácter político-identitario que tuvo uno de sus objetivos importantes en aumentar la autosuficiencia y levantar un conjunto de industrias locales.

También en los distritos italianos la identidad jugó ambos roles, como sostén del proceso de crecimiento económico endógeno y, por otro lado, expresando formas culturales y modos de ser locales que posibilitan la cooperación entre actores y aporta a la definición de la especialización productiva (Becattini, 1989). Esa identidad viva, actuante, como fuerza, se sustentaba en el pasado con historias comunes ocurridas; en el presente, a través de espacios de sociabilidad y civismo, y en el futuro a través de imaginarios que proyectaban la comunidad local. Así, pasado, presente y futuro deben estar interiorizados por la comunidad.

Es desde aquel propósito que podemos hacer una crítica al ideario del nacionalismo modernizador que acompañó los años de la emergencia de las estrategias de desarrollo. Si bien permitió afirmar ciertas ideas y buscar cambios progresistas en las décadas del '40-'6o, tuvo, en general y en aras de reforzar "lo nacional", un impacto de anulación de las iniciativas locales. Se vieron los territorios e identidades locales como carentes de valores modernos, incapaces de conducir procesos endógenos, en que esas identidades locales eran vistas como un obstáculo al progreso. Solo aparecía importante la configuración o reforzamiento de una identidad nacional, producida desde el centro y llevada a las periferias. 
Esta valorización de las identidades y culturas locales, en la doble dimensión de lo instrumental y lo simbólico, no tiene que entenderse como un esencialismo en que esos elementos configurantes de la territorialidad local están fijados y no tienen procesos de cambio. Tampoco como un fundamentalismo, en enfrentamiento radical con otras identidades. Las fronteras identitario-culturales de un proceso endógeno deben ser abiertas, aunque con fuerza propia.

Señalada la importancia de la identidad para los procesos endógenos, es importante preguntarse cómo fortalecerla. Para Arocena (2002), la identidad viene del reconocimiento de una historia colectiva, pero alcanza su mayor potencialidad al abrir preguntas sobre el presente y el proyecto futuro y, a partir de ella, se estimula la innovación y la producción de nuevos escenarios.

Siendo un buen punto de partida el anterior, reclama, sin embargo, considerar situaciones propias de las localidades y algunos procesos contemporáneos importantes, que problematizan la cuestión del fortalecimiento de las identidades locales.

Uno es el de las zonas de alto conflicto en el que exista una disputa fuerte por la orientación del territorio en cuanto a su forma de desarrollo. ¿Cómo pensar en ese caso, la posibilidad de un "nosotros" si hay una fuerte fractura y conflicto local? En ese caso, la disputa debe lograr generar un relato y un programa amplio que represente una parte mayoritaria de la sociedad local, que se reconozca en una identidad común que -a la vez- logra dar cuenta de identidades más específicas. Esta perspectiva, debe, a la vez, recoger las identidades históricas y emergentes de los grupos subalternos de la localidad, para que constituya no un elemento opresivo sino una(s) identidad(es) que represente(n) su integración como grupos protagonistas, haciendo del proceso endógeno un proceso democrático.

Un ejemplo de esta situación, por su expansión en países latinoamericanos -dado el estilo de desarrollo de estos últimos- es el de territorios con fuerte presencia de agentes y dinámicas extractivistas y en que, como respuesta, han surgido resistencias y "narrativas" desde grupos afectados y han dado origen a movimientos socioambientales (Leff, 2008; Svampa, 2008). Muchas veces fusionados con ese tipo de procesos, pero también, más allá de ellos, está la constitución de movimientos indigenistas ligados a la tierra y a espacios territoriales específicos. En este caso, sus formas de organizarse y hacer y sus identidades les diferencia respecto de otros actores que confluyen en el territorio. Esto muestra, seguidamente, una identidad entendida desde la resistencia a los procesos globalizantes y a las abruptas transformaciones que este impone en los territorios. Incluso el hecho de que varios de ellos reivindiquen el reconocimiento de su nacionalidad obliga a estrategias de desarrollo que comprenden en su raíz problemáticas de autodeterminación nacional, donde los componentes identitario y político son los protagonistas. 
También hemos visto que la globalización ha acentuado procesos que ya estaban instalados y que plantean preguntas sobre la real posibilidad de grados significativos de identidad local y que deben ser considerados en el análisis y la propuesta del desarrollo endógeno. Por un lado, está la visión de la disolución de las culturas locales en beneficio de una global, única, impuesta por centros de poder económico, político y cultural. Esto significa una pérdida de invención cultural asociada a territorios locales.

También, se ha señalado que estos últimos han experimentado procesos de descentramiento "material" por las múltiples y diversas redes que atan a las personas y grupos de un territorio con espacios y niveles supralocales. Se trataría de una copresencia de agentes y actividades, con poca articulación a la escala local. A la vez, una de las expresiones más evidentes del dinamismo actual es la movilidad y el tránsito en el territorio. Las áreas de movimiento dentro se ven acrecentadas, se amplía la escala de los espacios vitales y suele bajar el grado de arraigo a una territorialidad, que puede experimentarse como difusa o muy abstracta. La identidad, como una expresión cultural, deja de arraigarse en un espacio único, sino que refleja una especie de mestizaje múltiple, diverso, en un movimiento constante y jamás predecible. Esto está vinculado con el aumento de las migraciones y con ello la "liquidez" de la relación con muchos territorios que pueden experimentarse como "de paso" y con la actitud del "dilema del prisionero", esperando ser beneficiado por ciertas acciones o políticas, pero no involucrándose en ellas.

Se trata de procesos que pueden debilitar las posibilidades de desarrollo local endógeno. Sin embargo, hay elementos que, aun considerando la dosis de realidad de esa perspectiva, pueden contrarrestar tendencias a la "disolución de lo local", como espacios con algún grado de (auto)centramiento. En primer lugar, suele haber una historia que no es borrada y que tiende a reproducirse en la sociabilidad e instituciones locales. Una noción que ha destacado este fenómeno es el de lugarización, que hace referencia a los procesos que valorizan lo local y constituyen una realidad inversa a la de globalización. El lugar es un espacio propio con singularidades físicas y humanas; es el resultado de una historia enmarcada en un lugar específico y natural; es un tiempo/espacio dentro de una geo-historia. (González, 2009).

En segundo lugar, hay un margen de acción de la política local, que puede permitir generar procesos y orientaciones. Podríamos decir, que hay un espacio para la voluntad política (local) que puede construir fuerza. Esto se puede encontrar en iniciativas que buscan despertar interés y reencontrarse con la artesanía, las comidas, el turismo local, que enfrentan la fuerza a la estandarización de los estilos de vida.

Otro aspecto que empuja hacia grados de auto-centramiento (abierto) local es que una parte de las necesidades y demandas de las personas tienen el carácter de bienes comunes, como la calidad del ambiente, de los medios de locomoción, de los espacios 
verdes, del tipo de relaciones sociales, de la situación de la vejez, del cuidado de los recursos naturales y de la biodiversidad, etc. Ellos no se enfrentan (solo) como suma de intereses y conductas individuales y que, aunque tienen que ver con procesos más globales, tienen su expresión y especificidad en los territorios locales. Por último, los mismos procesos de deslocalización, descentramiento, fragmentación, redes hacia fuera, produce contra-tendencias que buscan reanimar espacios locales-comunitarios y enfrentar situaciones de anonimato extremo, más propios del mundo urbano.

Corresponde señalar también, que nuestra perspectiva de desarrollo endógeno y, en particular el componente identitario que reconocemos como parte de ello, se separa de la idea de "una identidad para competir". En esta perspectiva que criticamos, la identidad alcanza un sentido meramente instrumental como "capital" para tener más éxito en la globalización, caracterizado como un proceso que pone a "todos contra todos". El desarrollo local es asociado a la inserción exitosa en la globalización -en competencia con los otros territorios- más que a la calidad de vida de los habitantes y sujetos de la localidad. Bajo esta representación, la identidad local aparece como un componente de la competitividad en que los territorios con fuertes identidades logran encarnarla en sus productos y, con ello, agregarles un valor que les posiciona de mejor manera frente a otros productores y territorios. Por tanto, no se ve a la globalización como un proceso homogeneizador de la cultura, sino más bien como un proceso que obliga la valoración de la identidad, aunque dentro de un mega patrón cultural que es la competencia (González, 2011).

En nuestra perspectiva, la identidad local tiene un sentido que se arraiga en las personas y los colectivos, como una sociedad local, y, más allá de la utilidad del reconocimiento de un territorio dentro de un escenario más global, significa un valor en sí mismo, asociado a las necesidades de arraigo, identidad y otras, que poseemos.

\section{Conclusiones}

Como se pudo constatar, las perspectivas analizadas muestran una diversidad de maneras -aunque no todas excluyentes- de observar lo local en tiempos de globalización. Se pueden constatar enfoques que destacan fenómenos o propuestas como el "descentramiento", las redes supra locales, las resistencias ecoterritorisales, el reforzamiento de las capacidades competitivas de los territorios, el sentido comunitario y las identidades, etc. En general, esas aproximaciones tienden a implicar orientaciones para la acción y opciones ideológicas acerca de lo deseable, algunas opuestas entre sí. Incluso, tienen implicancias acerca de cuanto sentido tiene proponerse un desarrollo endógeno, que ha sido materia de la segunda parte del artículo.

Remarcamos, aquí, que el carácter de alternatividad y endogeneidad de los procesos locales de desarrollo no están dados automáticamente solo por la importancia de poderes locales a esa escala, sino también por las orientaciones económicas, culturales y sociales que predomine en las orientaciones de esos poderes. 
A modo de síntesis, planteamos que lo local -desde nuestra perspectiva- presenta escalas diversas y debe entenderse como un "complejo de locales" que pueden tener sinergias entre sí. Esta afirmación se basa en la idea de que el territorio se produce socialmente, y que los agentes lo construyen actuando desde diversas escalas de la realidad y desde diferentes tipos de relaciones entre ellos, ya sea de oposición, conflicto, negociación o cooperación. En este marco, para poder producirse el desarrollo local endógeno necesita de una sociedad local fortalecida, que cuente con un entramado complejo de relaciones entre actores que constituyan un escenario capaz de propiciar la endogeneidad del proceso.

Por otro lado, si el capital social es una condición básica, la red debe estar marcada por el aumento del peso de los sectores más subalternos. A la par, relevamos la importancia de la existencia de procesos estatales de descentralización, que representan una condición, pero también como un indicador y un objetivo del desarrollo local endógeno.

Este punto pone en evidencia un asunto central: no es posible pensar el desarrollo local endógeno desde el protagonismo exclusivo de los agentes locales. Las acciones en y desde escalas mayores pueden resultar claves si están en concordancia con orientaciones provenientes de las escalas locales y son capaces de relevar la realidad y posibilidad de la intervención significativa de ellos en las orientaciones respecto de diversas materias que inciden en la calidad de vida colectiva e individual. Pero también estas acciones supralocales pueden ser imprescindibles en contextos iniciales de altas desigualdades inter territoriales, donde las tareas del desarrollo local deben ser apoyadas por políticas que mejoren las posiciones estructurales de las comunidades locales desfavorecidas. Esto no es algo simple, pues es cierto que, por un lado, diversos problemas pueden ser resueltos -o intentar ser resueltos o agravados- por actores no locales; por otro lado, esas medidas implementadas pueden estar o no en concordancia con intereses y con objetivos autodefinidos por los actores locales.

Con todo, y esperamos haber contribuido en algo con este texto, es necesario seguir haciendo visibles las posibilidades que existen y aumentar el imaginario del espacio de acción local para transformar las condiciones territoriales existentes.

\section{Referencias}

Albagli, Sarita (1998). Globalização e Espacialidade: o novo papel do local. Rio de Janeiro: IE/UFRJ.

Arocena, José (2002). El desarrollo local: un desafío contemporáneo. Montevideo: Ediciones Taurus -Universidad Católica.

Arocena, José y Javier Marsiglia (2018). La escena territorial del desarrollo: Actores, relatos y políticas. Montevideo: Taurus. 
Becattini, Giacomo (1989). Riflessioni sul distretto industriale marshalliano come concetto socio-economico. Stato e Mercato, 25: 111-128.

Bervejillo, Federico (1996). Territorios en la globalización: cambio global y estrategias de desarrollo territorial. Santiago de Chile: ILPES.

Biocca, Mercedes (2020). Zonas de sacrificio. Neoextractivismo y pueblos indígenas en la era post-neoliberal. Etnografías Contemporáneas, 11: 106-112.

Boisier, Sergio (2005). ¿Hay espacio para el desarrollo local en la globalización? Revista de la CEPAL, 86: 47-62.

Bolivar, Antonio (2001). Globalización e identidades: (des)territorialización de la cultura. Revista Educación, Número Extraordinario, 265-288.

Bourdin, Alain (200o). La question locale. París: Presses Universitaires de France.

Canales, Manuel y Alejandro Canales (2012). La Nueva Provincia: (re)poblamiento de los territorios agrarios. Chile 1982-2002. Revista Anales, 7 (3): 155-173.

Canales, Manuel y María Cristina Hernández (2011). Del fundo al mundo. Cachapoal, un caso de globalización agropolitana. Espacio Abierto, 20 (4): 579-6o5.

Capnal, Lorena (2010). Feminismos Diversos, Feminismos Comunitarios. Segovia: ACSUR.

De Mattos, Carlos (1994). Modernización y estructuración global en Chile de la génesis autoritaria a la consolidación democrática. Cuadernos de Economía, 14 (20): 147-176.

Franco, Rolando y Ángela Gómez (2004). Gobernabilidad, gobernabilidad democrática y el papel de las políticas sociales. Anuario Social y Político de América Latina y el Caribe, 7: 93-101.

Friedmann, John (1996). Modular cities: Beyond the rural-urban divide. Environment and Urbanization, 8 (1): 129-131.

García Canclini, Néstor (1990). Culturas híbridas. Ciudad de México: Grijalbo.

Garofoli, Gioacchino (1992). Endogenous Development and Southern Europe. Avebury: Aldershot.

Garofoli, Gioacchino (2002). Local Development in Europe: Theoretical Models and International Comparisons. European Urban and Regional Studies, 9 (3): 225-239.

González, Francisco (2009). Desarrollo humano sustentable local. Revista de la Universidad Bolivariana, 8 (22): 53-66.

González, Raúl (2008a). Poderes Locales, Nación y Globalización. Santiago de Chile: Universidad Academia de Humanismo Cristiano.

González, Raúl (2008b). Los agentes de las dinámicas territoriales - El caso de ciudades intermedias chilenas. Revista Prisma, 22: 195-214. 
González, Raúl (2011). La identidad local en las visiones de desarrollo. Revista Lider, 18 (13): 79-94.

González, Raúl y Carlos Calderón (2018). Pensando la diversificación productiva como alternativa a las especializaciones mineras: el caso de Antofagasta, Chile. Revista Espacios, 7 (14): 74-99.

Hernández, Roberto y Carolina Vargas (2015). Micro-redes en comunidades indígenas de Chile: análisis antropológico de estas experiencias. Revista Márgenes Espacio Arte y Sociedad, 12 (17): 25-33.

Leff, Enrique (2006). La ecología política de América Latina. Un campo en construcción. En H. Alimonda (ed.), Los tormentos de la materia. Aportes para una ecología política latinoamericana. Buenos Aires: Clacso.

Leff, Enrique (2008). Discursos Sustentables. México D.F.: Siglo XXI Editores.

Lorenzoni, Gianni (1983). La costellazione di imprese: una base di indagine sui proceso di sviluppo. Economía e Política Industriale, 38.

Martínez Alier, Joan (2007). El ecologismo popular. Revista Ecosistemas, 16 (3): 148151.

Max Neef, Manfred, Antonio Elizalde y Martin Hopenhaym, M. (1986). Desarrollo a escala Humana. Una opción para el futuro. Londres: CEPAUR - Fundación Dag Hammarskjöld.

Ospina, Sonia (2001). Globalización y desarrollo local: hacia una perspectiva municipalista. Revista de Estudios Sociales, 8.

Perroux, Francois (1964). Economic Space: Theory and Applications. En J. Friedmann and William Alonso (eds.), Regional Development and Planning (pp. 21-36). EEUU: M.I.T. Press.

Pisani, Elena y Stefano Micheletti (2018). Capital social y desarrollo rural: revisión de los aportes europeos en investigación aplicada. Revista Pensamiento y Acción Interdisciplinaria, 4 (2): 4,4-59.

Quintero, María Liliana y Lizbet Gakkardo (2008). La estrategia de desarrollo local en el contexto de la globalización. Aldea Mundo, 13 (26): 39-48.

Robertson, Roland (200o). Glocalización: tiempo-espacio y homogeneidad. Zona abierta, 92 (93): 213-242.

Schiliró, Daniele (2008). I distretti italiani in Italia quale modello di sviluppo locale: aspetti evolutivi, potenzialitá e criticitá. Milano: Universitá Cattolica del Sacro Cuore.

Silveira, María Laura (2007). Los territorios corporativos de la globalización. Geograficando, 3 (3): 13-26. 
Sotelo, José Antonio y María Sotelo (2013). Desarrollo y Medio Ambiente en Madrid. Hacia un nuevo modelo de desarrollo urbano. Revista Electrónic@de Medioambiente, 14 (1): 22-55.

Svampa, Maristella (2008). La disputa por el desarrollo: territorio, movimientos de carácter socio-ambiental y discursos dominantes. En: M. Svampa. Cambio de época. Movimientos sociales y poder politico. Buenos Aires: Siglo XXI.

Svampa, Maristella (2016). Debates latinoamericanos. Indianismo, desarrollismo, dependencia y populismo. Buenos Aires: Edhasa.

Tolón, Alfredo y Xavier Lastra (2009). Planificación en los espacios rurales españoles. Aplicación del modelo neo-endógeno para un desarrollo sostenible en las comarcas de metodología LEADER. Observatorio Medioambiental, 12: 49-75.

Vásquez Barquero, Antonio (2005). Las nuevas fuerzas del desarrollo. Barcelona: Antoni Bosch editor.

Ward, Neil, Jane Atterton, Tae-Yeon Kim, Philip Lowe, Jeremy Phillipson y Nicola Thompson (2005). Universities, the Knowledge Economy and "Neo-Endogenous Rural Development". Centre for Rural Economy Discussion. Paper Series No. 1.

\section{Sobre los autores}

Raúl González Meyer. Universidad Academia de Humanismo Cristiano. Correo Electrónico: rgonzalezm@docentes.academia.cl. 1 https://orcid.org/0000-0002-3385$151 \mathrm{X}$

Stefano Micheletti. Escuela de Sociología, Centro de Estudios Urbano-Territoriales (CEUT). Facultad de Ciencias Sociales y Económicas. Universidad Católica del Maule. Correo Electrónico: smicheletti@ucm.cl. https://orcid.org/0000-0001-88095486 


\title{
CUHSO
}

Fundada en 1984, la revista CUHSO es una de las publicaciones periódicas más antiguas en ciencias sociales y humanidades del sur de Chile. Con una periodicidad semestral, recibe todo el año trabajos inéditos de las distintas disciplinas de las ciencias sociales y las humanidades especializadas en el estudio y comprensión de la diversidad sociocultural, especialmente de las sociedades latinoamericanas y sus tensiones producto de la herencia colonial, la modernidad y la globalización. En este sentido, la revista valora tanto el rigor como la pluralidad teórica, epistemológica y metodológica de los trabajos.

\author{
EDITOR \\ Matthias Gloël \\ CoORdinadora EDITORIAL \\ Claudia Campos Letelier \\ CorRector DE ESTILO Y DiSEÑAdor \\ Ediciones Silsag \\ TRADUCTOR, CORRECTOR LENGUA INGLESA \\ Aurora Sambolin Santiago \\ SITIO WEB \\ cuhso.uct.cl \\ E-MAIL \\ cuhso@uct.cl \\ LICENCIA DE ESTE ARTÍCULO \\ Creative Commons Atribución Compartir Igual 4.0 Internacional
}

